\title{
Studies on construction and running mode of university counselors learning organization construction
}

\author{
Yuan Zhang, Shiyong Lu \\ Shandong University, Jinan Shandong, 250101,China
}

Keywords: Counselor, Learning organization, Running mode, Evaluation system.

\begin{abstract}
Dynamic and complex interior and exterior environment requires for university counselors to systematically establish learning organizations. University counselors leaning organization is a multi-dimension organism made up by universities, function departments, learning teams and counselors themselves, in an operating mode of a dynamic process of learning motion, knowledge accumulation, analysis and decision, and shared innovation based on shared vision. To achieve the organization learning maximization, it is necessary to evaluate and adjust counselor learning organization from aspects of knowledge learning, knowledge application, shared innovation and knowledge infrastructure.
\end{abstract}

\section{Problem description}

With the high-speed development of knowledge economy and increasing display of college students' personality, in the open, dynamic, complicated and variable interior and exterior environment, colleges and universities have set higher requirement on counselor's knowledge reserve and application ability. Fast learning and applying to their practical work cannot be reached only by counselor's personal learning and training. Thus, it is necessary to accelerate to construct learning organization among university counselors and constantly improve tem and university counselors' adaptation and flexibility for interior and exterior dynamic environment so as to turn their individual advantages to collective advantages. Thus the issue has become a new focus in college and university moral and political work.

Learning organization is an organization which can proficiently create, obtain and transmit knowledge, and a blueprint for people to obtain life significance, achieve mutual vision and get competitive advantages. It combines individual working process with study so as to achieve the mutual development of individuals, teams and organizations. But there exist two problems in researches on university counselors leaning organizations: firstly, single theory dimension conflicts with the multi-dimension of university counselor's learning organization; secondly, established theories are usually formed through summarizing studies during enterprise development process thus with no big referential significance on the construction and operation of university counselor's learning organization. This research tries to discuss the construction and operation of university counselor's learning organization, the special group, from multiple aspects.

\section{Subject framework of university counselor's learning organization construction}

According to theory of dissipative structure, there exist multiple elements which form system integral behaviors and orderly result through mutual effect and coordinated operation . It means that learning organization as a form of organization should be an organism composed by multiple dimensions. Thus university counselor learning organization should be an activity process based on multi-learning subject coordinating operation, as well as a diversified subject structure. (See Fig. 1) 


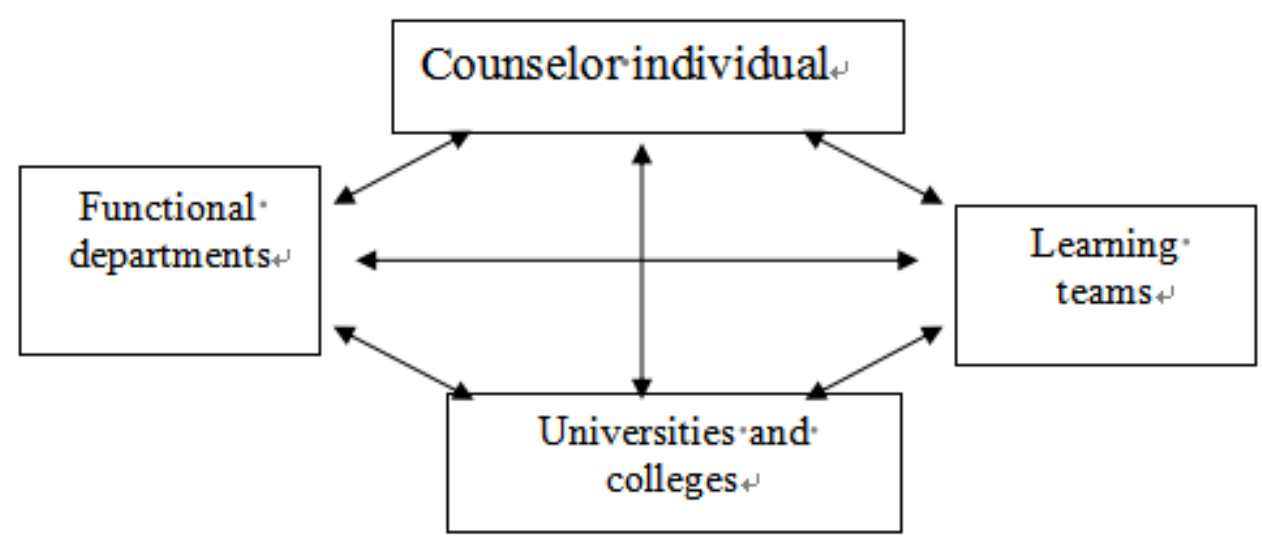

Fig. 2. University counselor's learning organization main structure diagram

\section{Subject of university counselor's learning organization---colleges and universities}

University counselor's learning organization subject has different properties and functions with other subjects as university counselor is the proposer and initiator of organization culture and values playing a vital role in constructing the environment and atmosphere of university counselor's learning organization. Meanwhile, college development and strategic direction have decided the target formulation and running mode of university counselor's learning organization to a large degree.

\section{Subject of university counselor's learning organization---functional department}

It mainly refers to each functional department and subsidiaries closely related to university counselor's learning organization, which are participants of learning process influencing the coordination and connection between counselors and terms, as well as the organizer or learning process on the other hands bearing the management and promotion work of learning organizations.

\section{Subject of university counselor's learning organization----learning team}

Each learning organization is made up by learning teams which make the coordination and synergistic effect become possible. Learning team is the center and important procedure of learning organization construction as well as the important carrier and direct bearer of learning organization. This means whether university counselor's learning organizations can be successfully established and operated is decided by whether learning teams can smoothly operate and produce effective results.

\section{Subject of university counselor's learning organization----counselor individual}

Counselor individual is the mini cell of learning organization. Individual learning can help learning organization to operate normally through promoting team learning. Meanwhile, counselor individual learning process is also the basis of constructing and developing learning organization. A lot of learning organizations are formed due to individual learning. As the subject of learning organization, counselor's individual learning decides whether learning team can operate normally but also decides the development of learning organization.

To sum up, subject university counselor's learning organization has established is a diversified framework structure which exists not independently and separately but integrating with each other to gradually establish the learning organization.

\section{Running mode of university counselor's learning organization}

Research result of organizational ecological theory shows that, learning organization is based on natural principles of similarity system engineering and ecological system so as to make organizations can operate according to natural ecological system functions for constant self-learning, self-organizing, and self-evolving and knowledge innovation, with quick response to complex 
environment. Thus, the running mode of university consoler's learning organization must integrate individual learning, organizational operation, target vision, and exterior environment. For university consoler's learning organization, its running mode is a dynamic process of learning motion, knowledge accumulation, analysis and decision, and sharing innovation based on shared vision under the guidance of organization target. In this process, teams and individuals in the organization has finished learning tasks, improved learning ability and formed new learning objectives and motives while achieving organizational targets (see Fig. 2).

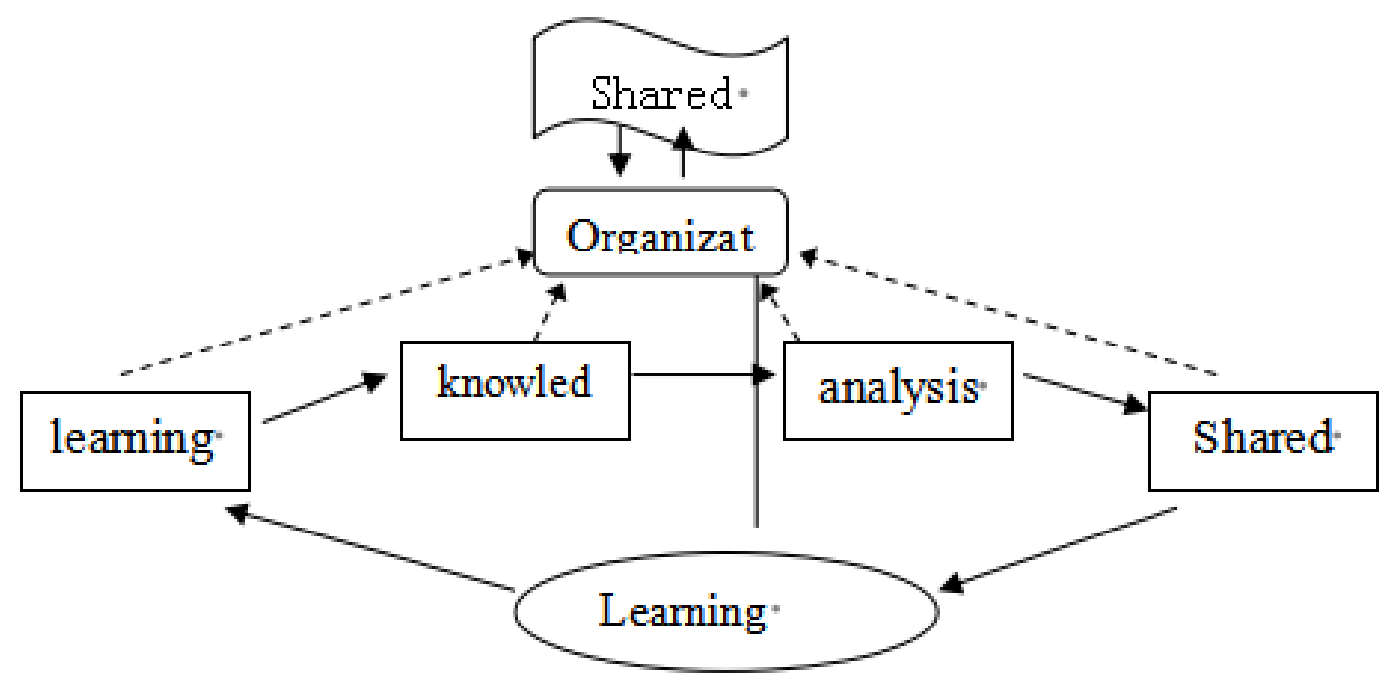

Fig. 2. University counselor's learning organization running mode diagram

\section{Learning motivation}

Learning motivation is the dynamical variable of organization learning, as well as a issue about the direction, intensity and duration, also the starting point of organization target oriented university consoler's learning organization. In most cases, learning motivation of learning organization mainly comes from interior factor and exterior factor. Exterior factor mainly refer to outside environmental demand; interior factor mainly comes from interest motivation of organization interior individuals and teams and the appeal for improving interior ability. Learning motivation has aroused the learning desire and improving momentum of university consoler's learning organization.

\section{Knowledge accumulation}

In economics, knowledge accumulation refers to the increase of knowledge quantity and sublimation of quality, and optimization of structure.Knowledge accumulation mentioned in this article mainly refers to the increase of knwlege quantity. The process of knowledge accumulation of university consoler's learning organization requires for system guarantee: establish and perfect university consoler's learning reward, system training, and information sharing system, so as to guarantee the knowledge acquirement in quantity. Meanwhile, it is also a process that individuals internalize obvious knowledge and then externalize so as to constantly update and expand the knowledge base inside organization.

\section{Analysis and decision}

Analysis and decision process of university consoler's learning organization is a process for reprocessing accumulated knowledge so that it can be better applied by individuals and organizations. Analysis is to investigate, classify and organize knowledge obtained in the knowledge accumulation process under the mutual vision and target of university consoler's learning organization. Decision refers to the process that university consoler's learning organization formulates and selects learning plans and methods suitable for organizational development under the precondition that university consoler's learning organization completed knowledge organization and analysis for the purpose of achieving organizational learning optimization. 


\section{Sharing and innovation}

Sharing and innovation is the stage displaying the ability of learning organization operation. For university consoler's learning organization, the sharing mechanism of knowledge learning is a process for knowledge transfer, learning, storage, and feedback in a sharing platform so as to achieve the goal of knowledge sharing organism. Sharing requires four subjects in university consoler's learning organization participated to establish the knowledge sharing between counselor individuals, individual and team, team and organization, and between teams, departments, and organizations

Innovation process emphasizes the counselor or teams' transforming knowledge to organizational ability in the learning process so as to improve or innovate new organizational development mode. Innovation is the essential breakthrough of university consoler's learning organization.

It should be noted that university consoler's learning organization running mode cannot be achieved at once for each learning subjects in the organization but constantly progress in an advanced, curved and cycling state, generally in a spiral rising movement so as to promote organization continuously step into higher level.

\section{University counseler's learning organization evaluation system}

It turns out that not all learning organizations are successful and smooth in operation process. Some organization have failed and suffered from huge damages in the implementation process.Thus, it is very necessary to establish reasonable and effective university consoler's learning organization evaluation for timely controlling the operation of university consoler's learning organization and provide help and reference for organizational development. Evaluation on university consoler's learning organization is mainly conducted from four aspects: learning ability, application ability, sharing innovation ability and infrastructure ability. (See Fig. 3)

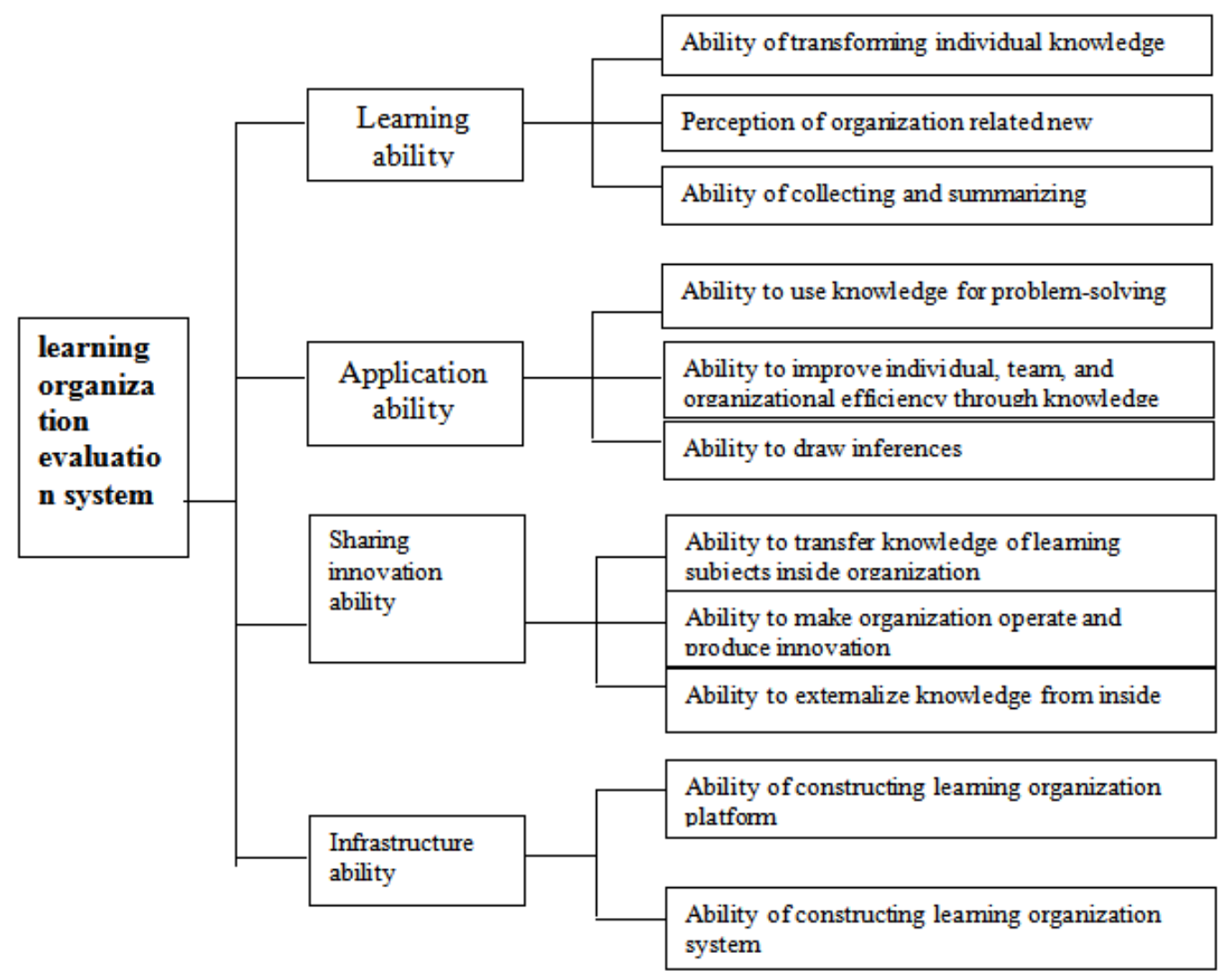

Fig. 3. Diagram of university consoler's learning organization evaluation system 


\section{Organization knowledge learning ability}

Organization knowledge learning ability refers to that organization or individuals or teams inside achieve the overall ability by using learning strategies or methods for knowledge searching, collecting, summarizing, selecting, absorbing and feedback. Evaluation on university consoler's learning organization learning ability is mainly conducted from following three aspects: 1 . Knowledge transforming ability, the ability of individual knowledge to be quickly transformed to organization knowledge so as to establish interior database. 2. Knowledge perception ability, the sensitivity to individual, team, and organization to knowledge in this fields. It can make sure that university consoler's learning organization can maintain flexibility and adaptation in variable environment. 3. Absorption and summarization ability, the process that university consoler's learning organization internalizes knowledge obtained and transforms into organization tacit knowledge.

\section{Organization knowledge application ability}

The direct purpose for any organizations to obtain knowledge is to apply knowledge and obtain organization benefits. So is university consoler's learning organization. Organization can develop and recreate knowledge in the process of knowledge application. The knowledge application ability of university consoler's learning organization is mainly reflected in following three aspects: 1 . Teams and individuals inside organization use knowledge to solve practical problems on the basis of internalizing knowledge. 2. Improve team or individual working efficiency through reasonable application of knowledge so as to improve organization efficiency. 3. The process of organization applying knowledge is also the process of understanding knowledge and solving problems. Repetitive knowledge application can help teams and individuals not blindly or mechanically use so as to own the ability of drawing inferences.

\section{Knowledge sharing and innovation ability}

Knowledge can be newly developed in the process of communication and sharing, which is the innovation process of knowledge recreation. Any forms of innovation is the accumulation of organization resources. Thus for university counselor's learning organization, knowledge sharing and innovation ability have decided the width and depth of organization development to a large degree. Knowledge sharing and innovation ability is mainly reflected in following three aspects: 1. Knowledge transfer and dispersion speed and validly of subjects inside university counselor's learning organization, which guarantees the knowledge sharing and fluency inside organization. 2. Organization cannot automatically innovate through interaction between subjects, thus whether organization can produce innovative activities and develop into organization innovation is the manifestation of organization sharing innovation ability. 3. Compare with explicit knowledge, tacit knowledge attracts organization's more attention due to its limited transfer ability and it has low knowledge regulation efficiency and information transmission efficiency, Thus, externalization of it into explicit knowledge can help organization to yield twice the results.

\section{Organization infrastructure building ability}

University counselor's learning organization construction and evaluation is a series of process requiring for support of environment, technology, tools and other elements. Infrastructure building ability is the supporting part of university counselor's learning organization, making knowledge resources inside organization more reasonably integrated and developed so as to promote the establishment of organization knowledge chain. Infrastructure building ability of university counselor's learning organization mainly includes organizational platform construction and system construction. The former mainly refers to technical guarantee and environmental support such as the creation of organizational cultural atmosphere, establishment and operation of information network technologies and database, construction of expert decision-making system, reward and punishment system, and training system formulation and execution so as to guarantee organization learning activity. 
Establishment of university counselor's learning organization can help universities and counselors to effectively obtain and apply knowledge to innovate so as to actively respond to social development and environmental change. From the perspective of researching interior organization, based on the practice of university counselor's work, this article has proposed the main framework, running mode, and evaluation system of university counselor's learning organization construction, for the purpose of helping counselor's knowledge coordination and individual development. Feasibility and applicability of university counselor's learning organization running mode and evaluation system have not be verified, thus universities and counselors need to combine with practice in future work for further researches.

\section{Reference}

[1] Peter Senge "The Fifth Discipline-art and practice of learning organization", Shanghai: Shanghai Sanlian Bookstore, 1998.

[2] Zhao Ling. Modern form of view of nature-ecological natural view of self-organization, Jilin University Journal Social Sciences Edition, 2001 (2).

[3] Yu Yanping, Long Jiancheng. Studies on knowledge-based ecological organization, Journal of Xidian University (social sciences edition), 2002(12).

[4] Yuan Xianxue. Research summary of organizational learning motivation, Journal of Southwest Normal Universsity (Social Science Edition), 2006(01).

[5] Qu Bingxiang. Marx's Theory of "Knowledge Accumulation" and its Modern Value, Contemporary Economic Research, 2013(01).

[6] Patricia M. Norman, Knowledge acquisition, knowledge loss, and satisfaction in high technology alliances, Journal of Business Research, 2004(57).

[7] Prescott C E. Innovation in the multinational firm with globally dispersed R\&D:Technological knowledge utilization and accumulation, The Journal of High Technological Management Research,1999,10(2).

[8] Li Wei, Wei Mintang, Wang Lin. Studies on tacit knowledge transfer mechanism, Journal of Information, 2005(4).

[9] Zhang Jianhua, Liu Zhongying. Analysis on knowledge management system factors, Scientific Management Research, 2005(2). 